\title{
Simultaneous gene quantitation of multiple genes in individual bovine nuclear transfer blastocysts
}

\author{
Craig Smith, Debbie Berg, Sue Beaumont, Neil T Standley, David N Wells and Peter L Pfeffer \\ AgResearch, Ruakura Campus, East Street, Hamilton, New Zealand \\ Correspondence should be addressed to P L Pfeffer; Email: peter.pfeffer@agresearch.co.nz
}

\begin{abstract}
During somatic cell nuclear transfer (NT), the transcriptional status of the donor cell has to be reprogrammed to reflect that of an embryo. We analysed the accuracy of this process by comparing transcript levels of four developmentally important genes (Oct4, Otx2, Ifitm3, GATA6), a gene involved in epigenetic regulation (Dnmt3a) and three housekeeping genes ( $\beta$-actin, $\beta$-tubulin and $G A P D H)$ in 21 NT blastocysts with that in genetically half-identical in vitro produced (IVP, $n=19)$ and in vivo ( $n=15)$ bovine embryos. We have optimised an RNA-isolation and SYBR-green-based real-time RT-PCR procedure allowing the reproducible absolute quantification of multiple genes from a single blastocyst. Our data indicated that transcript levels did not differ significantly between stage and grade-matched zona-free NT and IVP embryos except for Ifitm3/Fragilis, which was expressed at twofold higher levels in NT blastocysts. Ifitm 3 expression is confined to the inner cell mass at day 7 blastocysts and to the epiblast in day 14 embryos. No ectopic expression in the trophectoderm was seen in NT embryos. Gene expression in NT and IVP embryos increased between two- and threefold for all eight genes from early to late blastocyst stages. This increase exceeded the increase in cell number over this time period indicating an increase in transcript number per cell. Embryo quality (morphological grading) was correlated to cell number for NT and IVP embryos with grade 3 blastocysts containing $30 \%$ fewer cells. However, only NT embryos displayed a significant reduction in gene expression (50\%) with loss of quality. Variability in gene expression levels was not significantly different in NT, IVP or in vivo embryos but differed among genes, suggesting that the stringency of regulation is intrinsic to a gene and not affected by culture or nuclear transfer. Oct4 levels exhibited the lowest variability. Analysing the total variability of all eight genes for individual embryos revealed that in vivo embryos resembled each other much more than did NT and IVP blastocysts. Furthermore, in vivo embryos, consisting of 1.5 -fold more cells, generally contained two- to fourfold more transcripts for the eight genes than did their cultured counterparts. Thus, culture conditions (in vivo versus in vitro) have greater effects on gene expression than does nuclear transfer when minimising genetic heterogeneity.
\end{abstract}

Reproduction (2007) 133 231-242

\section{Introduction}

During mammalian reproduction, fertilisation of the oocyte results in the fusion of two haploid genomes and marks the beginning of a cascade of events leading to the activation of the embryonic gene transcription program. Remarkably, fertilisation can be completely bypassed and live offspring obtained by replacing the maternal genome with a diploid genome derived from a multitude of host cells in a process termed nuclear transfer (NT) or cloning (for reviews, see Hochedlinger \& Jaenisch 2002, Wilmut et al. 2002). This indicates that cytoplasmic factors present in the matured oocyte are able to reprogram the transcriptional state of the donor cell genome. The relatively low viability of NT embryos, with only a few percent of reconstructs reaching adulthood and a range of malformations observable (Wilmut et al. 2002), suggests that this reprogramming is inefficient. Errors in reprogramming cannot be ascribed to genetic causes as offspring of cloned animals displaying defects are normal (Shimozawa et al. 2002, Tamashiro et al. 2002, Wells et al. 2004). Thus, it is likely that epigenetic causes ('stable alterations in gene expression potential'; Jaenisch \& Bird 2003) underlie reprogramming defects. Epigenetic information is encoded by DNA methylation patterns and chromatin configuration, the latter including the types and modifications of histones as well as non-histone chromatin proteins including the polycomb/trithorax factors (Li 2002). That such epigenetic information differs between nuclear transfer and normal embryos has been well documented (Bourc'his et al. 2001, Dean etal. 2001, Kang et al. 2001, Santos et al. 2003).

As the expression of any given gene is a function of its epigenetic state (Li 2002, Jaenisch \& Bird 2003) and the available repertoire of transcription factors and 
modulators which impinge on its regulatory region, errors in epigenetic reprogramming would be predicted to affect the gene expression profile of the embryo. Epigenetic reprogramming during NT needs to result in the abolition of donor cell transcriptional status and its replacement with that of the embryo. However, expression of donorspecific genes has recently been observed in clones, showing that epigenetic reprogramming is incomplete (Gao et al. 2003, Ng \& Gurdon 2005). Such epigenetic memory can lead to some loss of viability as demonstrated for mouse cloning, where nuclear transfer embryos developed more efficiently in donor cell culture medium than in embryo culture medium (Chung et al. 2002, Gao et al. 2003). However, reprogramming errors leading to incorrect activation/regulation of embryonic genes are likely to have more serious consequences on embryo viability. Numerous loss-of-function studies in the mouse have demonstrated that the absence of single genes will lead to embryonic lethality (see www. informatics.jax.org). For the inner cell mass (ICM)specific gene Oct4, even a relatively small twofold change in transcript levels can lead to dramatic lineage fate changes (Niwa et al. 2000). Thus, the quantitative analysis of embryonic gene transcription in NTembryos is fundamental to understanding decreased viability.

A number of investigations have examined gene expression in IVP (in vitro produced) and NT embryos using RT-PCR (Daniels et al. 2000, 2001, Wrenzycki et al. 2001 b, Bortvin et al. 2003, Donnison \& Pfeffer 2004, Hall et al. 2005), reporter transgenes (Boiani 2002) and microarrays (Pfister-Genskow et al. 2005, Smith et al. 2005, Somers et al. 2006). To date, no clear picture has emerged of embryonic genes that are consistently misexpressed (Wrenzycki et al. 2005). This may not be surprising, considering that aspects of the nuclear transfer procedure including donor cell type, recipient cytoplast, activation protocols and culture methods differ among studies and some of these have been demonstrated to have an effect on gene expression (Daniels et al. 2001, Wrenzycki et al. 2001a). However, a further problem inherent to studies examining gene expression in preimplantation embryos concerns the technical difficulty of procuring accurate quantitative data when working with such small quantities of material. This has been partially solved by examining pools of embryos (Donnison \& Pfeffer 2004), performing semi-quantitative analyses (Daniels et al. 2000, 2001, Wrenzycki et al. 2001a, Hall et al. 2005), or recently, by using linear amplification before PCR (Camargo et al. 2005). However, as reprogramming may well result in small changes in transcript levels, it has become imperative to be able to distinguish subtle variations in individual embryos from variations due to technical noise.

We have sought here to develop a reproducible accurate assay allowing the quantification of multiple genes from a single blastocyst-stage embryo. Using this procedure, we examined the expression of a collection of developmentally important genes in individual NT as well as IVP and in vivo derived embryos. Our method, accurate enough to discern subtle gene expression differences between early, mid and late blastocyst stage embryos, yields insight into transcript level variation of multiple genes in single embryos and the effect of nuclear transfer, in vitro culture and embryo grading on embryonic gene transcription.

\section{Materials and Methods}

\section{Generation of in vivo, IVP and NT embryos}

Abbatoir recovered ovaries were aspirated with oocytes matured in vitro and used to generate either zona-free IVP or nuclear transfer (NT) blastocysts. Generation of IVP embryos by in vitro fertilisation (using sperm from bull AESF 1 ) is as previously described (Thompson et al. 2000) except for zona removal after fertilisation and single embryo culture. Bovine NT, using cultured skin fibroblasts recovered from bull AESF 1 and embryo culturing of both the IVP and NT embryos using a synthetic oviduct fluid system, with embryos cultured singly was performed as described elsewhere (Oback et al. 2003). Grading and staging of development according to published guidelines (Robertson \& Nelson 1998) was performed by only one of us (D N W). Briefly, zona-free blastocysts were classified as 'early' when a small blastocoel was visible, 'mid' when the blastocoel constituted approximately half the embryo and 'late' when the blastocyst had expanded. Grade 1 embryos were symmetrical with well-defined and uniform blastomeres. Grade 2 embryos had moderate irregularities in the shape or size of the inner cell mass or similar irregularities in the size, colour or density of the individual blastomeres. Grade 3 embryos had major irregularities in the size or overall shape of the ICM or the size, colour or density of the blastomeres. For in vivo embryos, eight Friesian cows were superovulated by i.m. injection of follicle-stimulating hormone (FSH) over 4 days with prostaglandin $\mathrm{F}_{2 \alpha}$ administered on the morning and evening of the first and third day of FSH treatment according to standard protocols. The cows were artificially inseminated 12 and $24 \mathrm{~h}$ after oestrus (day 0 ) with semen from bull AESF 1. Blastocysts were recovered by nonsurgical uterine flushing on day 7 . Embryos were classified as 'early', 'mid' and 'late' according to the guidelines above. This work was performed under animal ethics approval Ruakura-AE10051.

\section{Total RNA Isolation, DNase treatment and RT}

cDNA generation from blastocysts was optimised as follows. Single day 7 blastocysts were placed in $100 \mu$ l of Trizol (Invitrogen) to which $5 \mathrm{pg}$ rabbit $\alpha$-globin mRNA (Sigma) and 800 ng MS2 RNA (Roche) were added. The use of non-stick tubes (Neptune \#3435.S3, Raylab, Auckland, New Zealand) marginally enhanced 
recoveries. Samples were extracted with $20 \mu$ chloroform followed by the addition of $10 \mu \mathrm{g}$ linear acrylamide (Ambion, Austin, Texas, USA) and $65 \mu \mathrm{l}$ cold isoproanol. After $10 \mathrm{~min}$ at room temperature, samples were centrifuged at 14000 r.p.m. (16 $000 \mathrm{~g})$ for $30 \mathrm{~min}$, washed with $150 \mu \mathrm{l} 70 \%$ ethanol and air-dried. The use of phage MS2 RNA in addition to linear acrylamide as a carrier improved recoveries by up to fivefold. After resuspension in $7 \mu$ l diethylpyrocarbonate (DEPC)treated water, $2 \mu \mathrm{l} 1 \mathrm{U} / \mu \mathrm{l}$ RNase-free DNase1 (Invitrogen) and $1 \mu \mathrm{l} 10 \times$ DNase I buffer was added and samples incubated for $1 \mathrm{~h}$ at $37^{\circ} \mathrm{C}$. The samples were precipitated with $1.5 \mu \mathrm{l} 3 \mathrm{M}$ sodium acetate $(\mathrm{pH}$ 5.5) and $45 \mu \mathrm{l} 100 \%$ ethanol, washed in $70 \%$ ethanol and resuspended in $12 \mu \mathrm{l}$ DEPC-treated water.

For reverse transcription (RT), $1 \mu \mathrm{l}$ water, $1 \mu \mathrm{l} 10 \mathrm{mM}$ dNTP and $1 \mu \mathrm{l} 10 \mathrm{mM}$ oligo $\mathrm{dT}_{14} \mathrm{VN}$ anchored primer (Invitrogen) were added to $11 \mu \mathrm{l}$ of each sample before incubation at $65{ }^{\circ} \mathrm{C}$ for $5 \mathrm{~min}$. Four microlitres $5 \times$ first strand buffer (Invitrogen), $1 \mu \mathrm{l} 40 \mathrm{U} / \mu \mathrm{l}$ Protector RNase inhibitor (Roche), $1 \mu \mathrm{l} 200 \mathrm{U} / \mu \mathrm{l}$ Superscript III (Invitrogen) were added and the samples incubated at $50{ }^{\circ} \mathrm{C}$ for $60 \mathrm{~min}$, then $70{ }^{\circ} \mathrm{C}$ for $15 \mathrm{~min}$. A RT negative (RT-) control was included. This was followed by the addition of $0.5 \mu \mathrm{l} 2 \mathrm{U} / \mu \mathrm{l}$ RNAse $\mathrm{H}$ (Invitrogen) for $30 \mathrm{~min}$ at $37{ }^{\circ} \mathrm{C}$. After the addition of $2 \mu \mathrm{l}$ sodium actetate $(\mathrm{pH}$ 5.5), samples were passed through Qiaquick mini elute columns (Qiagen, Auckland, New Zealand) and resuspended in $40 \mu \mathrm{l}$ T0.1E buffer in $0.65 \mathrm{ml}$ non-stick tubes. In the RT reactions, omission of dithiothreitol and the use of anchored oligo-dT primers increased the consistency, though not the yield, of cDNA as measured using $\alpha$ globin mRNA. Importantly, inclusion of an $\mathrm{RNaseH}$ step after RT to digest RNA still bound to cDNA increased copy numbers fourfold. In this regard, an RNaseA digestion step reduced yields, presumably by digesting away the MS2 RNA carrier (data not shown).

\section{Real-time PCR}

We used SYBR-green based real-time RT-PCR for quantification using a Roche LightCycler 2 instrument with $10 \mu \mathrm{l}$ reactions containing $2 \mu \mathrm{l}$ FastStart DNA Master Sybr Green I reaction and enzyme mix (Roche), $4 \mathrm{nmol}$ of each primer, $80 \mathrm{ng}$ MS2 RNA and $2 \mu \mathrm{l}$ template. The thermal program included a $10 \mathrm{~min}$ incubation at $95{ }^{\circ} \mathrm{C}$ to activate the FastStart Taq polymerase followed by 45 cycles of $95{ }^{\circ} \mathrm{C}$ for $10 \mathrm{~s}$, annealing temperature (see Table 1) for $5 \mathrm{~s}$ and $72{ }^{\circ} \mathrm{C}$ for 10-20 s (this varied with amplicon size $-1 \mathrm{~s}$ for every 25 bps) with ramp speed $20{ }^{\circ} \mathrm{C} / \mathrm{s}$. The fluorescence readings were recorded after each $72{ }^{\circ} \mathrm{C}$ step. A no-template control, an RT - control and a standard dilution series were included in each real-time run. Dissociation curves were performed after each PCR run to ensure that a single PCR product had been amplified. The products were also analysed by gel electrophoresis and sequencing on first primer pair usage to ensure that the correct gene fragment was amplified.

We determined the sensitivity of detection and amplification efficiency for each gene-specific primer pair by preparing standard curves. The standard curves were obtained using PCR fragments that were excised from a $1 \%$ agarose gel, purified using a Roche Gel Extraction Kit, resuspended in TE and quantified with both a NanoDrop ND-1000 Spectrophotometer (NanoDrop, Wilmington, DE, USA) and fluorometrically with PicoGreen (Invitrogen) using the LightCycler. Standards consisted of a tenfold dilution series containing $10^{5}$ to $10^{1}$ copies/ $\mu$ I. PCR results from the LightCycler were compared with predicted values using an equation that relates reaction efficiency, $\mathrm{Cp}$ value (cycle number corresponding to the apex of second derivative of fluorescence intensity curve) and copy number (Wilkening \& Bader 2004). Only primer pairs that gave an amplification efficiency (the increase in product per PCR cycle) within 0.2 of the theoretical maximum of 2.0 were used for quantification (Table 1). We found amplification efficiencies to be highly reproducible between PCR experiments (within 0.04), but nevertheless included a standard curve for each run, as even a slight increase of 0.04 at an amplification efficiency of 1.9 would, after 30 cycles, cause an error in copy number estimation of $(1.94 / 1.90)^{30}=1.87$-fold or $87 \%$. Using this strategy, we observed typical variation in copy numbers of PCRs performed on different days of between 2 ( $\alpha$-globin) and $4 \%$ (Oct4).

Our standard curves indicated a loss of linearity between 20 and 200 copies, thus setting a limit to quantitation. As we were using only $1 / 20$ th of a blastocyst per PCR to allow for duplicates and the analysis of more than one gene per embryo, we introduced a stringent sensitivity criterion by performing duplicates at a one in two dilution. Only if the copy number lay well within the linear range, the dilution would yield the expected copy number. This criterion resulted in the rejection of many genes whose transcripts, though readily detectable by real-time or standard RT-PCR, were below the reliability/sensitivity threshold of quantification.

Sample concentrations calculated from the standard curves were converted into an estimate of copy number per blastocyst after correcting for recovery and RT losses using values obtained for $\alpha$-globin recovery.

\section{PCR primers}

PCR primers were designed using Vector NTI (Invitrogen) or obtained from the literature (Table 1). Where possible, primers were designed to cover putative introns as determined by comparison with genomic bovine sequences or the homologous mouse loci. For genes without a GenBank bovine sequence, the mouse sequence was blasted against the TIGR bovine database, and primers were designed from the TIGR sequence. 
Table 1 Primers for PCR.

\begin{tabular}{|c|c|c|c|c|c|c|}
\hline Gene & Primer sequence, $5^{\prime}$ to $3^{\prime}$, forward, reverse & Size $(b p)$ & Introns & PCR Effic & Ta & Reference \\
\hline Rabbit $\alpha$-globin & $\begin{array}{l}\text { GCAGCCACGGTGGCGAGTAT, } \\
\text { GTGGGACAGGAGCTTGAAAT }\end{array}$ & 256 & 2 & 1.89 & 56 & Davis et al. (1996) \\
\hline \multicolumn{7}{|l|}{ Housekeeping } \\
\hline$\beta$-actin & $\begin{array}{l}\text { CAGAAGGACTCGTACGTGGG, } \\
\text { TTGGCCTTAGGGTTCAGGG }\end{array}$ & 200 & 0 & 1.98 & 56 & Coussens \& Nobis (2002) \\
\hline$\beta$-tubulin & $\begin{array}{l}\text { CAGAGCAAGAACAGCAGCTACTT, } \\
\text { GTGAACTCCATCTCGTCСАTGСССТC }\end{array}$ & 228 & 1 & 1.91 & 56 & \\
\hline GAPDH & $\begin{array}{l}\text { CTCCCAACGTGTCTGTTGTG, } \\
\text { TGAGCTTGACAAAGTGGTCG }\end{array}$ & 222 & 2 & 1.97 & 56 & Coussens \& Nobis (2002) \\
\hline \multicolumn{7}{|l|}{ Inner cell mass } \\
\hline Oct4 & $\begin{array}{l}\text { CCAGGACATCAAAGCTCTTCA, } \\
\text { AAAACCACACTCGGACCA }\end{array}$ & 428 & 3 & 1.98 & 56 & Donnison \& Pfeffer (2004) \\
\hline Iftm3 & $\begin{array}{l}\text { ACGACCACGGTGATCAACATC, } \\
\text { TAGTGGCCTCCGTAGTTCTGC }\end{array}$ & 317 & 1 & 1.92 & 56 & \\
\hline \multicolumn{7}{|l|}{ Trophectoderm } \\
\hline$c d x 2$ & $\begin{array}{l}\text { GGCTCTCAGAGAGGCAGGTTAA, } \\
\text { AGCCTTGCAGGGAAGACA }\end{array}$ & 194 & 0 & 1.93 & 56 & \\
\hline IFNtau & $\begin{array}{l}\text { GCTATCTCTGTGCTCCATGAGATG, } \\
\text { AGTGAGTTCAGATCTCCACCСATC }\end{array}$ & 359 & 0 & 1.87 & 56 & Wrenzycki et al. (2001a) \\
\hline \multicolumn{7}{|c|}{ Primitive endoderm } \\
\hline Gata6 & $\begin{array}{l}\text { ACCGGCCACTACCTTTGCA, } \\
\text { GCTGCAGTCATCTGCGTTAGAAG }\end{array}$ & 367 & 2 & 1.90 & 56 & \\
\hline$H N F 4 \alpha$ & $\begin{array}{l}\text { TGATGAGTTGGTGCTGCCCT, } \\
\text { TGTAGGGCTCGGACCCTGAA }\end{array}$ & 503 & 3 & 1.84 & 60 & \\
\hline \multicolumn{7}{|l|}{ Reprogramming } \\
\hline Dnmt3a & $\begin{array}{l}\text { CTGGTGCTGAAGGACTTGGGC, } \\
\text { CAGAAGAAGGGGCGGTCATC }\end{array}$ & 317 & 1 & 1.83 & 56 & Golding \& Westhusin (2003) \\
\hline HDAC1 & $\begin{array}{l}\text { ACTACTACGACGGGGATGTTG, } \\
\text { GCCAAGACGATATCATTGACG }\end{array}$ & 428 & 1 & 1.88 & 56 & McGraw et al. (2003) \\
\hline HDAC2 & $\begin{array}{l}\text { GACATATGAGACTGCAGTTGC, } \\
\text { АССТCСТTCTCСTTCATCCTC }\end{array}$ & 355 & 3 & 1.80 & 56 & McGraw et al. (2003) \\
\hline HAT1 & $\begin{array}{l}\text { CAGATATATAAGGCTGACATGAC, } \\
\text { GCTGTAATATCAAGAACTGTAGG }\end{array}$ & 345 & 3 & 1.77 & 56 & McGraw et al. (2003) \\
\hline GCN5 & $\begin{array}{l}\text { CAGAATGTCTTTTCCCACCAG, } \\
\text { GGATTCAGCTCACACTCCATC }\end{array}$ & 401 & 2 & 1.85 & 56 & McGraw et al. (2003) \\
\hline Trithorax & $\begin{array}{l}\text { ССССТTCССАССАСТССАТT, } \\
\text { GCTTTGGGGACTCСТGGAAT }\end{array}$ & 405 & 0 & & 56 & \\
\hline \multicolumn{7}{|l|}{ Signalling } \\
\hline BMP4 & $\begin{array}{l}\text { CTCAGGGCAGAGCCATGAGCT, } \\
\text { CGTCTCTGGGATGCTGCTGA }\end{array}$ & 317 & 1 & 1.81 & 56 & \\
\hline Wnt3a & $\begin{array}{l}\text { AGGCCATCGCCAGTCACATG, } \\
\text { TCCTGGCAGCTGACGTAGCA }\end{array}$ & 445 & 1 & & 58 & \\
\hline \multicolumn{7}{|l|}{ Metabolism } \\
\hline Glut1 & $\begin{array}{l}\text { AGGAGCTGTTCCACССССТGGGAGCTGACT, } \\
\text { TGTGGGTGAAGGAGACTCTGGCTGATAAAA }\end{array}$ & 327 & 0 & 1.90 & & Wrenzycki et al. (1999) \\
\hline Connexin 44 & $\begin{array}{l}\text { CGGAAGGAGCGTGAGGAGGAGC, } \\
\text { GGAGGCAGAGGGCGCGTAGT }\end{array}$ & 519 & 0 & & 64 & \\
\hline HSP70.1 & $\begin{array}{l}\text { AAGGTGCTGGACAAGTGCCAGGAGGTGATT, } \\
\text { ACTTGGAAGTAAACAGAAACGGGTGAAAAA }\end{array}$ & 488 & 0 & 1.85 & 60 & Wrenzycki et al. (1999) \\
\hline \multicolumn{7}{|c|}{ (1) } \\
\hline Nnat & $\begin{array}{l}\text { TTTTCGAAATCCTCCAGGGACAC, } \\
\text { TTGTCGGTGCTGCTTCTCCA }\end{array}$ & 309 & 1 & & 60 & Ruddock et al. (2004) \\
\hline \multicolumn{7}{|l|}{ Other } \\
\hline Otx2 & $\begin{array}{l}\text { CAATGCAGTCACCAGCCATCTCAA, } \\
\text { TGCCTCCTGGGACATTGATCA }\end{array}$ & 335 & 1 & 1.95 & 56 & \\
\hline gp130 & $\begin{array}{l}\text { GGCCGTGTACCTGTTCCTTA, } \\
\text { CCAGGTATGTTTCCCTTCCA }\end{array}$ & 257 & 1 & & 55 & \\
\hline$I L-6$ & $\begin{array}{l}\text { TGCAGTCTTCAAACGAGTGG, } \\
\text { ACATTCAAGCCACATAGCCA }\end{array}$ & 377 & 0 & & 56 & \\
\hline LIFR & $\begin{array}{l}\text { CGCACAGATGATGGACATTT, } \\
\text { CCGCTTTTCAATGCAAACTT }\end{array}$ & 265 & 1 & 1.94 & 56 & Coussens \& Nobis (2002) \\
\hline Traube & $\begin{array}{l}\text { TGGTAGATCTCCAGGAAGAGTTG, } \\
\text { CTCAGGAAGGATCTCCGGCT }\end{array}$ & 464 & 2 & 1.77 & 56 & \\
\hline
\end{tabular}

Ta, annealing temperature; Effic., efficiency of PCR reaction. 


\section{Cell counting of blastocyst embryos}

The number of cells in day 7 blastocysts was determined by either: (1) counting the Giemsa stained nuclei of fixed embryos spread onto glass slides; or (2) by combining the differential cell counts of the trophectoderm and ICM using procedures as previously described (Iwasaki et al. 1990). In vivo embryos were obtained as described above using a total of 20 animals in two separate experiments.

\section{Whole mount in situ hybridisation}

Zona-free IVP or NT blastocysts (from bull AESF 1) were fixed for $30 \mathrm{~min}$ at RT in $4 \%$ paraformaldehyde in PBS containing $0.1 \%$ Tween-20, then dehydrated in a methanol series and kept at least overnight at $-20{ }^{\circ} \mathrm{C}$. Day 14 embryos were recovered by flushing 7 days after day 7 IVP embryos were bulk transferred to synchronised recipient cows (McMillan et al. 2001). Day 14 embryos were slit open and fixed for $1 \mathrm{~h}$ at RT. Whole mount in situ hybridisation was performed as described (Nagy et al. 2003), but washing and hybridisation steps were performed in four-well plates (\#176740; Nunc, Auckland, New Zealand) with embryos transferred during steps rather than replacing solutions. The post-rehydration Proteinase K (Roche) digestion contained $10 \mu \mathrm{g} / \mathrm{ml}$ enzyme and was done for $30 \mathrm{~s}$ for zona-free embryos. The embryos were photographed with a Nikon Coolpix digital camera mounted on an inverted microscope.

A bovine Ifitm3/Fragilis PCR fragment (primers in Table 1) was cloned into pGEM-T easy in the SP6 orientation and antisense digoxygenin-labelled RNA produced by T7 RNA polymerase transcription (Roche) after plasmid linearisation by Spel digestion according to standard protocols.

\section{Statistics}

The log of the expression for each gene was analysed by treatment (NT/IVP/AI), stage, quality (grades 1 and 2 were usually combined) and their interactions to give means and standard error of differences of means using the linear model routine in GenStat (VSN International, Oxford, UK) that accommodated unequal numbers of blastocysts in each group. Variances, calculated separately for each treatment/stage/quality combination as the S.D. of the $\log$ of the mean expression level, were compared using Bartlett's test.

\section{Results}

\section{Expression levels at the blastocyst stage of a set of 26 bovine genes}

We wished to examine the expression of genes which would either be important for early development or be involved in reprogramming (Table 1). Of the 26 genes examined, six could not be detected in our quantitative assay using 1/20th of a blastocyst as input. Of these, Wnt3a, Trithorax, Connexin44, IL-6, Gp130 and the putatively imprinted gene Neuronatin fell within the nonlinear range of detection when using a full blastocystequivalent amount of cDNA, indicating that these genes are expressed at less than 200 copies per embryo.

Of the remaining 20 genes, 12 could be detected in $1 / 20$ th of a blastocyst but fell within the non-quantifiable region. Using full-blastocyst equivalents of cDNA, we confirmed that the transcript levels of these genes lay in the 200-2000 copies per blastocyst range. All of the histone modification enzymes (HDAC1 and 2, HAT1 and GCN5) as well as Cdx2, BMP4, HNF4a, LIF receptor, Traube, Interferon- $\tau$, Hsp70 and Glut 1 were expressed at these levels.

The housekeeping genes $\beta$-actin, $\beta$-tubulin and $G A P D H$ as well as one gene involved in reprogramming (the DNA methyltransferase Dnmt3a) and the lineage restricted genes Oct4, Otx2, Ifitm3 and GATA6 could be reliably quantitated in 1/20th of a blastocyst and we focussed on these genes for our subsequent analyses. Average expression levels of these eight genes were 4000-100 000 copies per blastocyst embryo (Fig. 1).

\section{Comparison of gene expression in individual NT, IVP and in vivo blastocysts}

We measured gene expression levels of eight genes in individual staged and graded day 7 embryos derived by NT $(n=21)$, IVP $(n=19)$ or in vivo embryos $(n=15)$. Zona-free NT and IVP embryos were cultured in parallel. In vivo and IVP embryos were fertilised with sperm from the same animal that was used to generate the NT embryos, thus ensuring a large degree of genetic identity between the different categories of embryos. An overall comparison of expression levels in transferable grade 1 and 2 embryos (Fig. 1) revealed a highly significant effect of embryo type (in vivo/IVP/NT) on transcript levels for all genes (actin, $P=0.03$; Oct4, $P<0.01$; others, $P<0.001)$. This effect is predominantly due to the higher transcript levels of the in vivo embryos (Fig. 1). Refining our analysis to stage matched groups revealed that in vivo embryos contained two- to fourfold more mRNA than both IVP and NT blastocysts for all genes at most stages (exceptions where $P>0.05$ were actin at earlier stages, Oct4 at late blastocyst stage, Ifitm3 compared with mid- and late blastocyst NT embryos and Dnmt3a compared with mid-blastocyst IVP embryos). We observed 1.5-fold higher cell numbers in in vivo embryos (Fig. 3). Interestingly, stage-matched NT and IVP embryos exhibited remarkably similar gene expression levels with consistent differences in expression levels at all stages seen only for the gene Ifitm3/Fragilis $(P<0.01$ across all stages and $P=0.02$ at early and $P=0.03$ at late blastocyst stage). However, the increase in expression was small with levels 2.5-, 1.5- and 1.6-fold higher in early, mid and late NT than in IVP blastocysts (Fig. 1). 

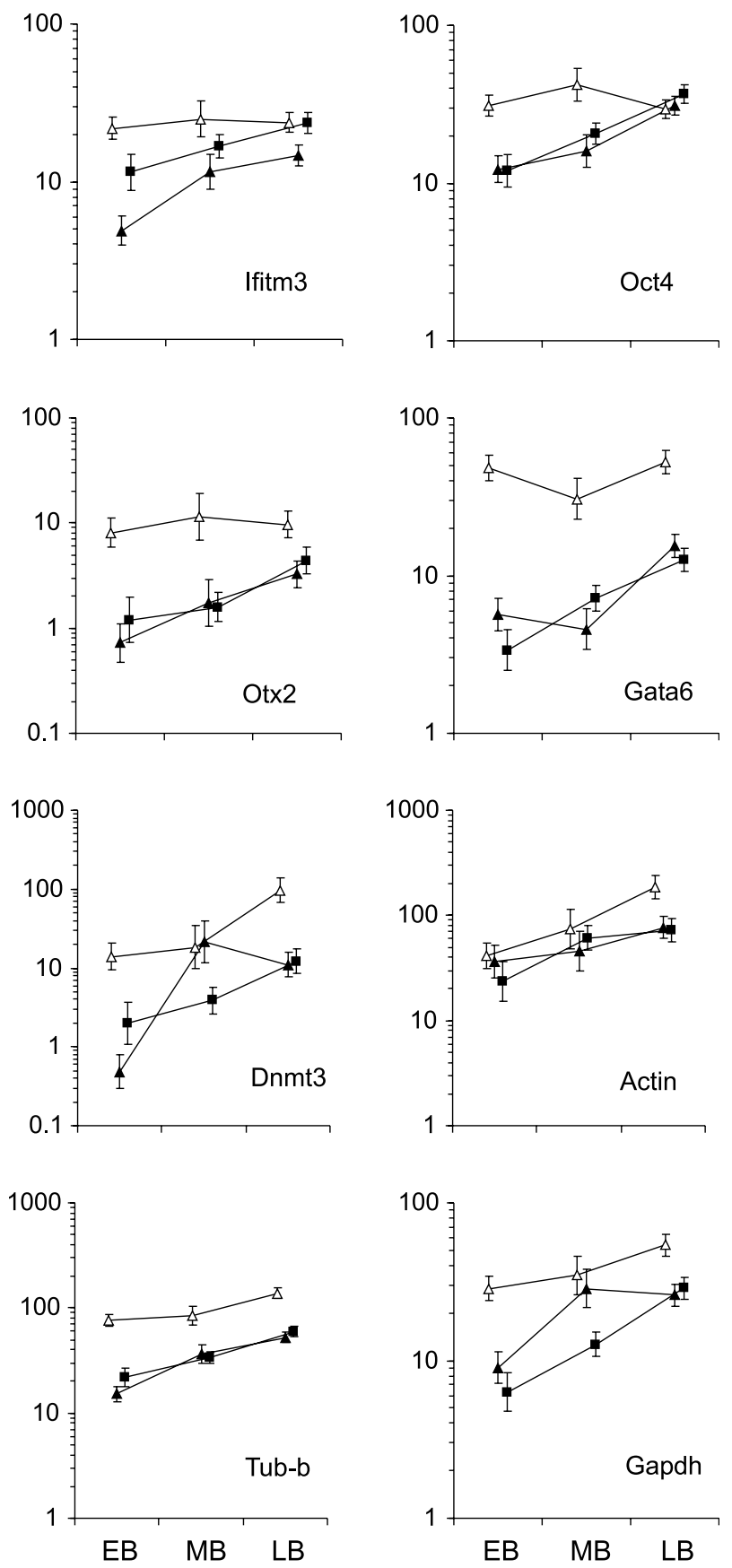

Figure 1 Average gene expression levels in NT, IVP and in vivo day 7 transferable grade blastocysts as determined by real-time RT-PCR. Solid squares represent NT (grade 1 and $2, n=13)$ solid triangles IVP $(n=11)$ and open triangles in vivo $(n=13)$ embryos. Error bars represent the S.E.M. The $Y$-axis shows transcript numbers in thousands. EB, early blastocyst; MB, mid blastocyst; LB, late blastocyst stage.

\section{Temporal effects on gene expression}

We noted a highly significant embryo-stage effect on gene transcription in transferable grade embryos $(P<0.01$ for all genes). IVP and NT gene expression increased between two- and threefold for all eight genes from early to late stages (Fig. $1, P<0.05$ ). Counting cell numbers in 120 NT and 69 IVP zona-free embryos revealed no significant difference between these two groups (Fig. 2). However, grade 1 and 2 late blastocysts contained 1.5- to 1.3-fold (NT and IVP respectively; $P<0.05)$ more cells than early blastocysts, with earlyand mid-blastocyst cell numbers not being significantly different from each other. Thus, whereas cell number is correlated to gene expression levels, both increasing with developmental age, the increase in gene expression exceeds the increase in cell numbers over this period, suggesting that the number of transcripts per cell is also increasing.

It should be pointed out that the temporal increases in gene expression were more subtle or not seen in in vivo embryos (Fig. 1), even though average cell numbers increased from 130 (S.E.M. $\pm 7 ; n=12$ ) to 160 (S.E.M. \pm 8 ; $n=13$ ) between mid- and late-stage blastocysts (Fig. 2).

\section{The effect of nuclear transfer and in vitro culture on gene expression variability}

We compared gene expression variability of transferable grade NT, IVP and in vivo embryos grouped according to developmental stage. Figure 3A depicts the variability for each of the genes at late blastocyst stages where we could compare the largest number of transferable grade embryos ( $n=6$ for each type of embryo). None of the differences in variability was significant (Bartlett's test, $P>0.1$ for all eight genes). Similar results were seen at earlier stages with only one exception (Dnmt3a at mid blastocyst; $P=0.03)$. We conclude that individual gene expression variance is equal for in vivo, IVP and NT embryos.

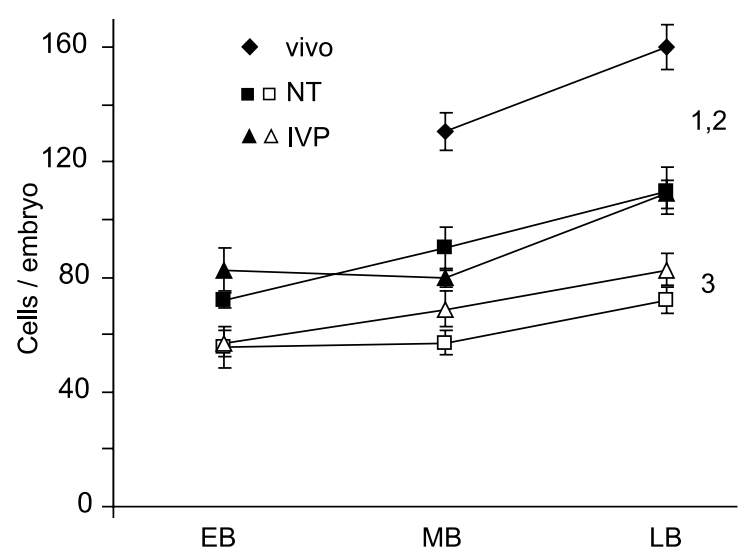

Figure 2 Cell numbers per blastocyst in in vivo and zona-free NT and IVP day 7 blastocysts. Solid symbols show transferable grade 1 and 2 embryos, open symbols grade 3. NT embryos $(n=120)$ are depicted by squares, IVP $(n=69)$ by triangles, in vivo $(n=25)$ by diamonds. ANOVA analysis for the zona-free embryos indicated no treatment effect (NT versus IVP), but significant grading (grades 1 and 2 vs 3 ) and a staging effects whereby early (EB) and mid (MB) blastocysts contained significantly fewer cells than late blastocysts $(\mathrm{LB})(P<0.05)$. Error bars represent S.E.M. 

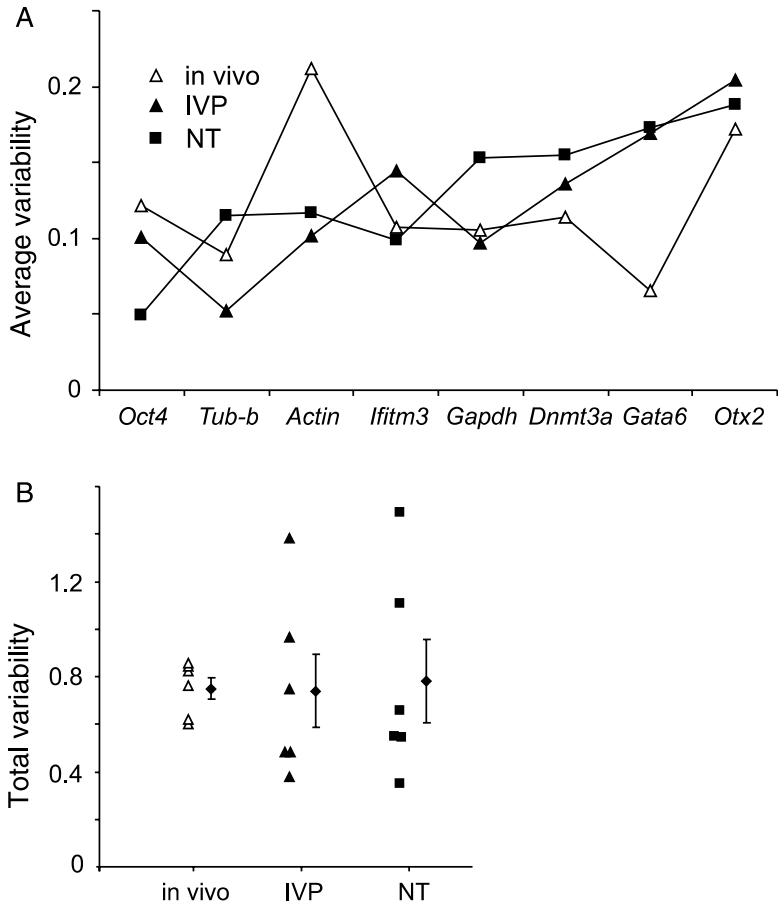

Figure 3 Gene expression and embryo variability in NT, IVP and in vivo late blastocyst stage transferable grade embryos. All values depicted here are based on a set of six embryos of each type. (A) Average variability representing the S.D. from the log of the mean expression level of each gene is depicted for the three types of embryo analysed. Genes are arranged on the $X$-axis in order of increasing variability. (B) The total variability for each embryo across all eight genes analysed was calculated by summing the absolute value of the deviation of that embryo from the mean expression level (residual) for each gene. The mean total variability and S.E.M. there of is depicted next to each group of embryos by a filled diamond and error bars.

As this study measured eight different genes from a single embryo, we could ask the question as to how different genes behaved within a single embryo. To this end, we summed the residuals (deviation from the log of the average expression level) for all genes of each latestage transferable grade embryo (Fig. 3B). As expected from the previous analysis, the average sum of residuals (diamonds in Fig. 3B) is nearly identical for all the three types of embryos. However, individual in vivo embryos deviated much less from this average than did the NT or IVP embryos (see range and s.E.M. bars in Fig. 3B). This implies that in vivo embryos are more alike to each other when including gene expression data from many genes than are the cultured embryos.

\section{Relationship of grading to gene expression}

We next examined gene expression in grade 3 embryos which are normally not transferred to recipients. Comparing late stage grade 1 with grade 3 IVP embryos revealed a slight reduction in transcription levels for five out of the eight genes, but this reduction was not significant apart for Gata6 (Fig. 4A). In marked
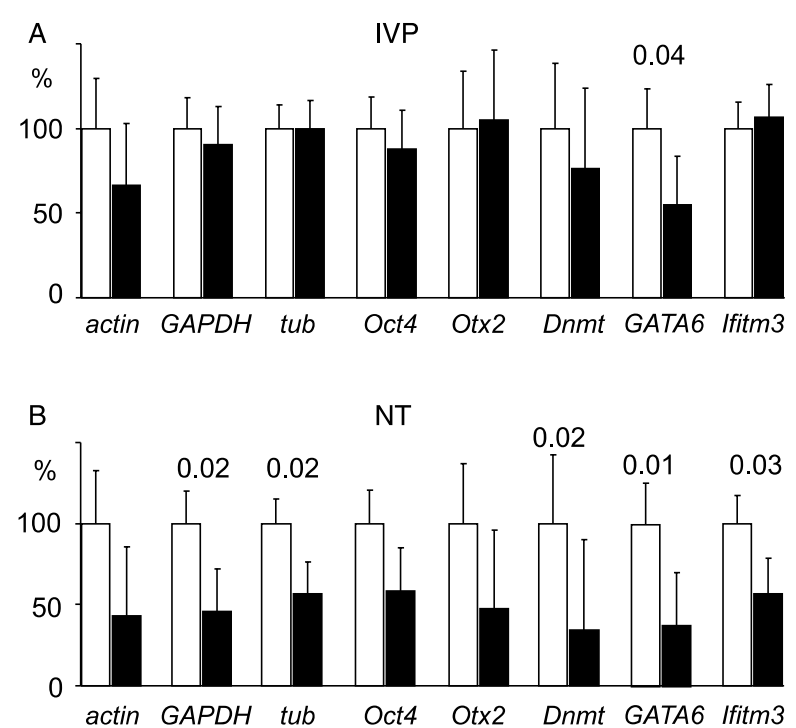

Figure 4 Embryo grade is correlated with gene expression levels in NT but not IVP embryos. Transcript levels in grade 3 blastocysts (black bars) are expressed as a percentage of levels in grade 1 blastocysts for IVP (Panel A) and NT (Panel B) embryos. Significance levels of the differences between grade 1 and 3 embryos are depicted where relevant. Only late blastocyst stage embryos are shown. Error bars are the S.E.M.

contrast, gene expression levels in grade 3 NT embryos were only $42-62 \%$ of that of grade 1 NT blastocysts. Most of these differences were significant below the $5 \%$ level (Fig. 4B). This difference in gene expression between grade 3 IVP and NT embryos can not be attributed to differences in cell numbers as both IVP and NT grade 3 embryos contained very similar cell numbers (Fig. 2). At the late blastocyst stage, grade 3 IVP embryos contained $65 \%$ as many cells as transferable grades, whereas for NT embryos the value was $75 \%$. Thus, although grade 3 embryos show a highly significant reduction in cell number per embryo, gene expression is only concommitantly significantly reduced in NT embryos. The differential behaviour of grade 3 IVP and NT embryos suggests that such embryos, though morphologically similar, are different at a molecular level.

\section{Spatial pattern of Ifitm3 expression}

Ifitm 3 was the only gene significantly misexpressed when comparing NT and IVP embryos. Whole mount in situ hybridisation revealed that Ifitm3 expression is restricted to the ICM in day 7 bovine blastocysts (Fig. 5A). We next asked whether the significant upregulation of this gene in NT embryos could be attributed to ectopic expression in the trophectoderm. However, in all embryos examined $(n=11)$, Ifitm3 expression was confined to the ICM (Fig. 5B). Ifitm3 expression remains confined to the epiblast at later stages in IVP (Fig. 5D) as well as NT embryos (data not shown). 

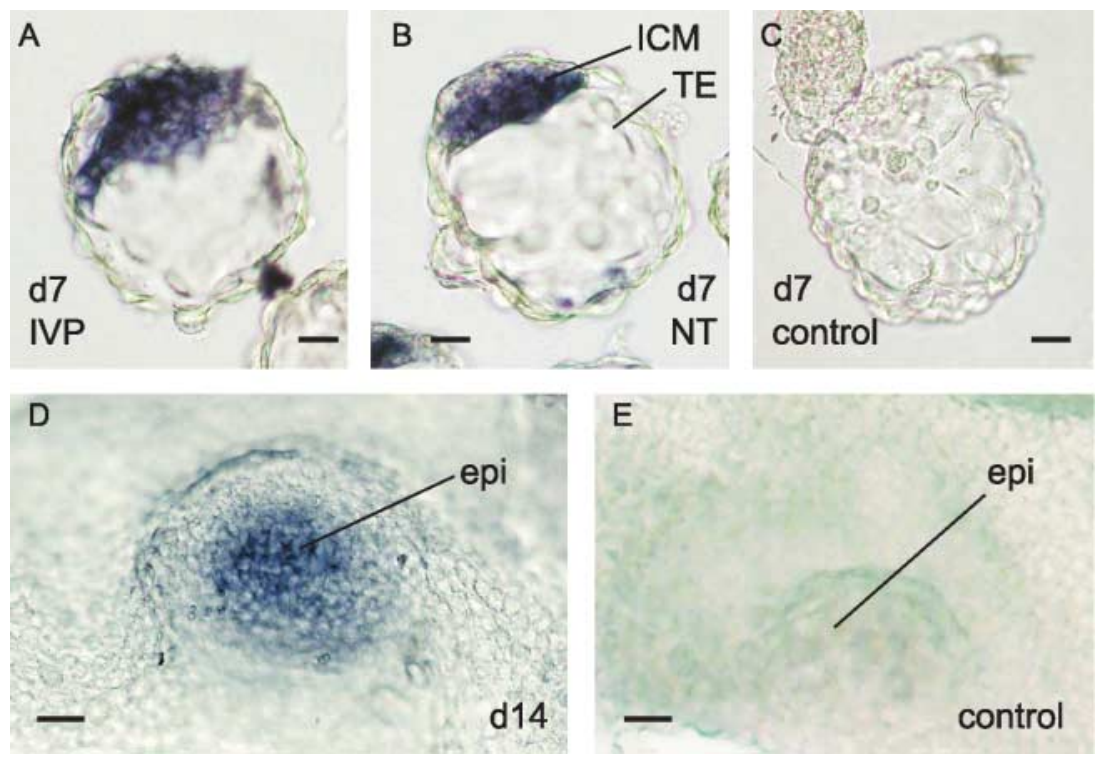

Figure 5 Spatial pattern of Ifitm3 expression in bovine embryos. Whole mount in situ hybridisation of zona-free day 7 IVP (panel A), NT (panel B) and day 14 bovine embryos (panel D). At blastocyst stages, Ifitm 3 expression is confined to the inner cell mass (ICM) with no expression seen in the trophectoderm (TE). By day 14, expression is still confined to the epiblast (epi) which is derived from the ICM. Panels $\mathrm{C}$ and $\mathrm{E}$ are embryos hybridised to a control (sense) probe, scale bar is $20 \mu \mathrm{m}$.

\section{Discussion}

\section{Effects of somatic cell nuclear transfer}

The primary focus of this work was to examine the effect of nuclear transfer on gene expression in individual blastocysts. Our approach centred on the ability to accurately quantify transcript levels of multiple genes in a single blastocyst. We thus developed a robust cDNA isolation scheme and have introduced criteria aimed at eliminating technical variation in our data (described in detail in the Materials and Methods section). We found three criteria to be crucial for accurate quantification. First, the addition of an exogenous spike - rabbit $\alpha$-globin mRNA, (Temeles et al. 1994, Donnison \& Pfeffer 2004) - was essential as housekeeping genes (internal standards) are themselves subject to reprogramming effects. Second, the inclusion of a standard curve with each experimental run eliminated significant errors arising through small changes in amplification efficiencies. The use of $\Delta \Delta \mathrm{Ct}$ should be avoided except in instances where the amplification efficiencies of the two genes compared is demonstrated to be equal. Third, performing duplicates at a higher dilution ensured that samples were within the linear range, where quantification is meaningful.

In this study, we minimized genetic effects by comparing NT embryos with IVP and in vivo embryos sharing $50 \%$ genetic identity with the NT embryos by virtue of being generated using sperm from the bull from which the skin fibroblast donor cells were derived. Furthermore, by culturing NT embryos in parallel to IVP embryos under identical (zona-free) conditions, effects specific to the NT procedure as opposed to gene expression differences arising due to embryo culture (Wrenzycki et al. 2005) can be addressed. On the other hand, the inclusion of in vivo embryos allows comparisons with a more physiological state. Does nuclear transfer affect gene expression at the blastocyst stage? Based on the simultaneous expression data for eight different genes, transferable grade NT embryos are remarkably similar to their genetically half-identical IVP embryos. This result is in line with other studies (Camargo et al. 2005, Somers et al. 2006). For seven of the genes, expression levels did not differ significantly at blastocyst stages. As several of the analysed genes (Oct4, Otx2, Gata6, Dnmt3a) are not expressed in skin fibroblasts (Smith et al. 2005), this suggests that reprogramming of these genes has occurred correctly. Secondly, with two exceptions (Dnmt3a and Gapdh at mid blastocyst), the time course of gene activation is highly similar in NT and IVP embryos, increasing at similar rates in a developmental series based on the morphological criteria of blastocyst formation and expansion. Importantly, the increase in gene expression (two- to threefold) exceeded the increase in cell numbers (1.3- to 1.5 -fold) over this developmental period, suggesting that the number of transcripts per cell was also increasing.

Thirdly, NT and IVP embryos resembled each other in that the level of embryo-to-embryo variation for all genes did not differ significantly, suggesting that the NT procedure does not cause any of the analysed genes to be consistently expressed in a less controlled manner than in the IVP counterparts. Lastly, by virtue of having measured multiple genes in single embryos, we could obtain a measure of the total gene expression variability of individual embryos. Bearing in mind that this measure represents only a small sample of the more than 10000 genes expressed at blastocyst stages, our results indicated wide variation among single embryos ranging 
from some closely resembling 'normality' - as characterised by approaching the average expression level of most genes - to distinctly aberrant embryos. However, as compared to IVP embryos, the mean and distribution of total gene expression variability of NT embryos did not differ. It is intriguing to speculate whether such 'abnormal' NT and IVP embryos are developmentally compromised. Considering the lower viability of NT embryos, one might have expected a larger fraction of such abnormal embryos in this treatment group. This question will only be resolved by future studies in which development of biopsied embryos is followed.

A recent report claimed that NT embryos are more similar in gene expression to in vivo than to IVP embryos (Smith et al. 2005). In our hands, it is in vivo embryos that differ the most in several aspects from their in vitro grown half-siblings and from genetically related NT embryos. For all eight genes and at most morphological stages, transferable grade in vivo embryos contain the most transcripts, generally between two- and fourfold more than the cultured zona-free blastocysts. Only part of this increase can be explained by the 1.5 -fold higher cell counts of in vivo embryos. A trend for higher relative gene transcript levels in in vivo blastocysts has been previously reported (Tesfaye et al. 2004, Camargo et al. 2005), though lower levels of gene transcripts have also frequently been seen (for recent review see Wrenzycki et al. 2005 and references therein). Furthermore, zona removal, a necessary requirement for our NT procedure, potentially may influence gene expression (Ribas et al. 2006). The pertinent point here is that culture per se (inclusive of zona removal) may have a stronger influence on gene expression levels than does the nuclear transfer treatment.

Intriguingly, in vivo gene expression levels do not differ as much between the morphologically early and late blastocyst stages as in cultured embryos. Thus, the changes in gene expression levels between in vivo and cultured embryos are most pronounced at early stages. A likely explanation accounting for this observation is that morphological staging of in vivo zona intact and cultured zona-free embryos does not relate equally to number of cell division and thus developmental stage. It has been observed that in vivo embryos commence blastulation (our morphological landmark) one cell cycle later than cultured embryos and complete this process much more rapidly (Van Soom et al. 1997). Thus, morphologically early in vivo blastocysts are more equivalent in developmental stage and cell number to in vitro mid blastocysts.

In contrast to overall expression levels, variability of expression for any of the eight genes analysed is not significantly different between the two types of cultured and the in vivo blastocysts. The variability in levels appears to be intrinsic to genes, as different genes show different average S.D. of the log of the average expression with more highly expressed genes generally, but not always, displaying less variation in their levels. Notably, Oct4 shows the least variability in expression (1.25-fold; compared with Otx2 variation of 1.5 -fold) in line with reports that twofold variation in this gene's expression levels can induce lineage changes in mouse ES cells (Niwa et al. 2000). Interestingly, when comparing gene expression profiles on an individual embryo basis, in vivo embryos show much lower total variability, when comparing many genes than their NT or IVP counterparts. Thus, in vivo embryos are more normal/alike to each other in terms of their gene expression levels. This question has not been addressed before using a quantitative assay. In one microarray experiment, bovine NT blastocysts were seen to show the lowest embryoto-embryo variation, followed by in vivo, then IVP, embryos (Smith et al. 2005). IVP embryos in this study were not related to NT or in vivo embryos and were genetically heterogeneous, whereas NT embryos were genetically identical to each other. The in vivo embryos were derived from two sets of siblings. This might suggest that genetic homogeneity reduces gene expression variability. Though the results are not directly comparable, our results clearly demonstrate albeit for a small set of genes that in genetically equivalent embryos (in vivo and IVP - all one sire) culture per se is sufficient to induce increased total gene expression heterogeneity. The genetic homogeneity of NT embryos is not sufficient to reduce this heterogeneity caused by in vitro culture, possibly because of increased epigenetic variation through incomplete reprogramming.

In this study, we discovered a notable effect when extending our analyses to grade 3 NT and IVP embryos. Only grade 3 NT embryos revealed significant reductions in expression levels for nearly all examined genes. This suggests that grade 3 NT embryos, which can be morphologically recognised, are also abnormal in terms of their gene expression profile. This effect is not simply due to a loss in cell numbers as grade 3 IVP embryos show a similar cell number reduction compared to transferable grade embryos as do NT blastocysts yet gene transcription is minimally affected. Furthermore, the loss in NT grade 3 cell number (around $30 \%$ ) is less than the loss in gene expression (around $50 \%$ ). As we generally do not transfer grade 3 zona-free NT embryos to recipients, we presently do not know if the observed changes in gene expression specific to grade 3 NT embryos reflect differences in viability.

\section{Ifitm3 and embryonic development}

The only gene differentially expressed between NT and IVP embryos was Ifitm3. Levels of this gene were elevated in NT embryos by about twofold at all blastocyst stages. Ifitm3 (interferon-induced transmembrane protein 3), also known as 1-8U/Mil1/Fragilis, is highly interferon-inducible (Lewin et al. 1991). Members of this family have been implicated in homotypic adhesion and 
in mediating an interferon-dependent anti-proliferative effect (Evans et al. 1990, 1993, Brem et al. 2003). Specifically, Ifitm3 overexpression reduces proliferation rates in human cell lines (Brem et al. 2003). Ifitm3 expression marks the onset of germ cell competence in the epiblast of pregastrula stage mouse embryos, and its expression at later stages remains associated with primordial germ cells (Saitou et al. 2002, Tanaka \& Matsui 2002). It has been proposed that the function of Ifitm3 in this system is twofold: first, that it is involved, through homotypic adhesion, in the segregation of prospective germ cells from surrounding somatic cells and second, that it mediates the observed increase in cell cycle time in nascent germ cells from 6 to $16 \mathrm{~h}$ (Saitou et al. 2002).

Previous to this report Ifitm3 expression could not be detected at the blastocyst stage in mice (Tanaka \& Matsui 2002). Our results indicate levels of around 10000 transcripts of Ifitm3 in the bovine blastocyst, with levels rising from early to expanded blastocyst stages. Interestingly, we found Ifitm 3 expression to be restricted to the inner cell mass in line with transcripts being detected in mouse ES cells (Saitou et al. 2002). This expression is maintained in the ICM/epiblast until at least day 14 . In the mouse, it appears that the transforming growth factor- $\beta$ factor BMP4 lies upstream of Ifitm3 (Saitou et al. 2002). Transcripts for Bmp4 (200-2000 copies/embryo) were detected in our analyses and our unpublished data suggests that this gene's expression is restricted to the ICM, raising the possibility that it may be involved in Ifitm3 transcriptional activation.

Why are Ifitm3 transcript levels elevated in NT embryos? Our whole mount in situ hybridisation results exclude the possibility of ectopic expression in the TE. The observation that offspring of defective animals created by nuclear transfer are normal strongly points to epigenetic changes causing defects. Such epigenetic changes are most likely due to the requirement for extensive chromatin remodelling of the donor nucleus. Hence, those genes most dependent on chromatinremodelling activities for their expression would be predicted to be most affected by nuclear transfer. In this regard, it is relevant to note that the Ifitm3 promoter is highly sensitive to the chromatin-remodelling activity of the SWI/SNF-like ATPase dependent BAF complex (Liu et al. 2002).

Would elevated expression of Ifitm 3 be expected to affect embryo viability? Increased Ifitm 3 mRNA levels in the ICM of NT embryos could be expected to reduce the proliferation rate of ICM cells eventually biasing the ICM:TE ratio to TE (trophectoderm). However, it should be noted that when comparing late-blastocyst NT Ifitm3 levels to in vivo embryos, there is no significant difference, suggesting that the observed increase in Ifitm3 expression relative to IVP embryos should not have adverse consequences on NT embryo viability.
In conclusion, this study represents the first report of the simultaneous absolute quantification of several genes in individual blastocysts, allowing new insights into transcript fluctuations and the effects on transcription levels resulting from somatic cell nuclear transfer as well as in vitro embryo culture. We have discovered the upregulation in NT embryos of a gene not hitherto explicitly associated with blastocyst specific expression.

\section{Acknowledgements}

We thank Andria Green, Pavla Misica, Fleur Oback, Jan Oliver, Anita Schurmann, Hilda Troskie as well as Dr Björn Oback for their help with the production of embryos, Martin Berg for animal treatments and husbandry, Harold Henderson for statistical assistance and Dr Jim Peterson for critical reading of the manuscript. This work was supported by the New Zealand Foundation for Research, Science and Technology. The authors declare that there is no conflict of interest that would prejudice the impartiality of this scientific work.

\section{References}

Boiani M, Eckardt S, Scholer HR \& McLaughlin KJ 2002 Oct-4 distribution and level in mouse clones; consequences for pluripotency. Genes \& Development 16 1209-1219.

Bortvin A, Eggan K, Skaletsky H, Akutsu H, Berry DL, Yanagimachi R, Page DC \& Jaenisch R 2003 Incomplete reactivation of Oct-4-related genes in mouse embryos cloned from somatic nuclei. Development 130 1673-1680.

Bourc'his D, Le Bourhis D, Patin D, Niveleau A, Comizzoli P, Renard JP \& Viegas-Pequignot E 2001 Delayed and incomplete reprogramming of chromosome methylation patterns in bovine cloned embryos. Current Biology 11 1542-1546.

Brem R, Oraszlan-Szovik K, Foser S, Bohrmann B \& Certa U 2003 Inhibition of proliferation by $1-8 \mathrm{U}$ in interferon-alpha-responsive and non-responsive cell lines. Cellular and Molecular Life Sciences $601235-1248$.

Camargo LS, Powell AM, Filho VR \& Wall RJ 2005 Comparison of gene expression in individual preimplantation bovine embryos produced by in vitro fertilisation or somatic cell nuclear transfer. Reproduction, Fertility, and Development 17 487-496.

Chung YG, Mann MR, Bartolomei MS \& Latham KE 2002 Nuclearcytoplasmic 'tug of war' during cloning: effects of somatic cell nuclei on culture medium preferences of preimplantation cloned mouse embryos. Biology of Reproduction 66 1178-1184.

Coussens PM \& Nobis W 2002 Bioinformatics and high throughput approach to create genomic resources for the study of bovine immunobiology. Veterinary Immunology and Immunopathology $\mathbf{8 6}$ 229-244.

Daniels R, Hall V \& Trounson AO 2000 Analysis of gene transcription in bovine nuclear transfer embryos reconstructed with granulosa cell nuclei. Biology of Reproduction 63 1034-1040.

Daniels R, Hall VJ, French AJ, Korfiatis NA \& Trounson AO 2001 Comparison of gene transcription in cloned bovine embryos produced by different nuclear transfer techniques. Molecular Reproduction and Development 60 281-288.

Davis W Jr, De Sousa PA \& Schultz RM 1996 Transient expression of translation initiation factor elF-4C during the 2-cell stage of the preimplantation mouse embryo: identification by mRNA differential display and the role of DNA replication in zygotic gene activation. Developmental Biology 174 190-201. 
Dean W, Santos F, Stojkovic M, Zakhartchenko V, Walter J, Wolf E \& Reik W 2001 Conservation of methylation reprogramming in mammalian development: aberrant reprogramming in cloned embryos. PNAS 98 13734-13738.

Donnison M \& Pfeffer PL 2004 Isolation of genes associated with developmentally competent bovine oocytes and quantitation of their levels during development. Biology of Reproduction 71 1813-1821.

Evans SS, Lee DB, Han T, Tomasi TB \& Evans RL 1990 Monoclonal antibody to the interferon-inducible protein Leu-13 triggers aggregation and inhibits proliferation of leukemic B cells. Blood 76 2583-2593.

Evans SS, Collea RP, Leasure JA \& Lee DB 1993 IFN-alpha induces homotypic adhesion and Leu-13 expression in human B lymphoid cells. Journal of Immunology 150 736-747.

Gao S, Chung YG, Williams JW, Riley J, Moley K \& Latham KE 2003 Somatic cell-like features of cloned mouse embryos prepared with cultured myoblast nuclei. Biology of Reproduction 69 48-56.

Golding MC \& Westhusin ME 2003 Analysis of DNA (cytosine 5) methyltransferase mRNA sequence and expression in bovine preimplantation embryos, fetal and adult tissues. Gene Expression Patterns 3 551-558.

Hall VJ, Ruddock NT \& French AJ 2005 Expression profiling of genes crucial for placental and preimplantation development in bovine in vivo, in vitro, and nuclear transfer blastocysts. Molecular Reproduction and Development 72 16-24.

Hochedlinger K \& Jaenisch R 2002 Nuclear transplantation: lessons from frogs and mice. Current Opinion in Cell Biology 14 741-748.

Iwasaki S, Yoshiba N, Ushijima H, Watanabe S \& Nakahara T 1990 Morphology and proportion of inner cell mass of bovine blastocysts fertilized in vitro and in vivo. Journal of Reproduction and Fertility 90 279-284.

Jaenisch R \& Bird A 2003 Epigenetic regulation of gene expression: how the genome integrates intrinsic and environmental signals. Nature Genetics 33 245-254.

Kang YK, Koo DB, Park JS, Choi YH, Chung AS, Lee KK \& Han YM 2001 Aberrant methylation of donor genome in cloned bovine embryos. Nature Genetics 28 173-177.

Lewin AR, Reid LE, McMahon M, Stark GR \& Kerr IM 1991 Molecular analysis of a human interferon-inducible gene family. European Journal of Biochemistry 199 417-423.

Li E 2002 Chromatin modification and epigenetic reprogramming in mammalian development. Nature Reviews. Genetics 3 662-673.

Liu H, Kang H, Liu R, Chen X \& Zhao K 2002 Maximal induction of a subset of interferon target genes requires the chromatin-remodeling activity of the BAF complex. Molecular and Cellular Biology 22 6471-6479.

McGraw S, Robert C, Massicotte L \& Sirard MA 2003 Quantification of histone acetyltransferase and histone deacetylase transcripts during early bovine embryo development. Biology of Reproduction 68 383-389.

McMillan WH, Wells DN, Peterson AJ \& Donnison M 2001 Early embryo development in nuclear transfer clones derived from somatic cells of a high genetic merit cow. British Society of Animal Science Occasional Publication 26 437-440.

Nagy A, Gerstenstein M, Vintersten K \& Behringer R 2003 Manipulating the Mouse Embryo: a Laboratory Manual, edn 3 Cold Spring Harbor: Cold Spring Harbor Laboratory Press.

Ng RK \& Gurdon JB 2005 Epigenetic memory of active gene transcription is inherited through somatic cell nuclear transfer. PNAS 102 1957-1962.

Niwa H, Miyazaki J \& Smith AG 2000 Quantitative expression of Oct$3 / 4$ defines differentiation, dedifferentiation or self-renewal of ES cells. Nature Genetics 24 372-376.

Oback B, Wiersema AT, Gaynor P, Laible G, Tucker FC, Oliver JE, Miller AL, Troskie HE, Wilson KL, Forsyth JT et al. 2003 Cloned cattle derived from a novel zona-free embryo reconstruction system. Cloning and Stem Cells 5 3-12.

Pfister-Genskow M, Myers C, Childs LA, Lacson JC, Patterson T, Betthauser JM, Goueleke PJ, Koppang RW, Lange G, Fisher P et al.
2005 Identification of differentially expressed genes in individual bovine preimplantation embryos produced by nuclear transfer: improper reprogramming of genes required for development. Biology of Reproduction 72 546-555.

Ribas RC, Taylor JE, McCorquodale C, Mauricio AC, Sousa M \& Wilmut I 2006 Effect of zona pellucida removal on DNA methylation in early mouse embryos. Biology of Reproduction 74 307-313.

Robertson I \& Nelson R 1998 Certification and identification of the embryo. In Manual of the International Embryo Transfer Society, pp 103-134. Eds AD Stringfellow \& SM Seidel. International Embryo Transfer Society: Illinois, USA.

Ruddock NT, Wilson KJ, Cooney MA, Korfiatis NA, Tecirlioglu RT \& French AJ 2004 Analysis of imprinted messenger RNA expression during bovine preimplantation development. Biology of Reproduction 70 1131-1135.

Saitou M, Barton SC \& Surani MA 2002 A molecular programme for the specification of germ cell fate in mice. Nature 418 293-300.

Santos F, Zakhartchenko V, Stojkovic M, Peters A, Jenuwein T, Wolf E, Reik W \& Dean W 2003 Epigenetic marking correlates with developmental potential in cloned bovine preimplantation embryos. Current Biology 13 1116-1121.

Shimozawa N, Ono Y, Kimoto S, Hioki K, Araki Y, Shinkai Y, Kono T \& Ito $\mathbf{M} 2002$ Abnormalities in cloned mice are not transmitted to the progeny. Genesis 34 203-207.

Smith SL, Everts RE, Tian XC, Du F, Sung LY, Rodriguez-Zas SL, Jeong BS, Renard JP, Lewin HA \& Yang X 2005 Global gene expression profiles reveal significant nuclear reprogramming by the blastocyst stage after cloning. PNAS 102 17582-17587.

Somers J, Smith C, Donnison M, Wells DN, Henderson H, McLeay L \& Pfeffer PL 2006 Gene expression profiling of individual bovine nuclear transfer blastocysts. Reproduction 131 1073-1084.

Tamashiro KL, Wakayama T, Akutsu H, Yamazaki Y, Lachey JL, Wortman MD, Seeley RJ, D'Alessio DA, Woods SC, Yanagimachi R et al. 2002 Cloned mice have an obese phenotype not transmitted to their offspring. Nature Medicine 8 262-267.

Tanaka SS \& Matsui Y 2002 Developmentally regulated expression of mil-1 and mil-2, mouse interferon-induced transmembrane protein like genes, during formation and differentiation of primordial germ cells. Mechanisms of Development 119 S261-S267.

Temeles GL, Ram PT, Rothstein JL \& Schultz RM 1994 Expression patterns of novel genes during mouse preimplantation embryogenesis. Molecular Reproduction and Development 37 121-129.

Tesfaye D, Ponsuksili S, Wimmers K, Gilles M \& Schellander K 2004 A comparative expression analysis of gene transcripts in postfertilization developmental stages of bovine embryos produced in vitro or in vivo. Reproduction in Domestic Animals 39 396-404.

Thompson JG, McNaughton C, Gasparrini B, McGowan LT \& Tervit HR 2000 Effect of inhibitors and uncouplers of oxidative phosphorylation during compaction and blastulation of bovine embryos cultured in vitro. Journal of Reproduction and Fertility 118 47-55.

Van Soom A, Boerjan ML, Bols PE, Vanroose G, Lein A, Coryn M \& de Kruif A 1997 Timing of compaction and inner cell allocation in bovine embryos produced in vivo after superovulation. Biology of Reproduction 57 1041-1049.

Wells DN, Forsyth JT, McMillan V \& Oback B 2004 The health of somatic cell cloned cattle and their offspring. Cloning and Stem Cells 6 101-110.

Wilkening S \& Bader A 2004 Quantitative real-time polymerase chain reaction: methodical analysis and mathematical model. Journal of Biomolecular Techniques 15 107-111.

Wilmut I, Beaujean N, de Sousa PA, Dinnyes A, King TJ, Paterson LA, Wells DN \& Young LE 2002 Somatic cell nuclear transfer. Nature 419 583-586.

Wrenzycki C, Herrmann D, Carnwath JW \& Niemann H 1999 Alterations in the relative abundance of gene transcripts in preimplantation bovine embryos cultured in medium supplemented with either serum or PVA. Molecular Reproduction and Development 53 8-18. 
Wrenzycki C, Wells D, Herrmann D, Miller A, Oliver J, Tervit R \& Niemann H 2001 a Nuclear transfer protocol affects messenger RNA expression patterns in cloned bovine blastocysts. Biology of Reproduction 65 309-317.

Wrenzycki C, Herrmann D, Keskintepe L, Martins A Jr, Sirisathien S, Brackett B \& Niemann H 2001 b Effects of culture system and protein supplementation on mRNA expression in pre-implantation bovine embryos. Human Reproduction 16 893-901.

Wrenzycki C, Herrmann D, Lucas-Hahn A, Korsawe K, Lemme E \& Niemann H 2005 Messenger RNA expression patterns in bovine embryos derived from in vitro procedures and their implications for development. Reproduction, Fertility, and Development 17 23-35.

Received 7 April 2006

First decision 16 May 2006

Revised manuscript received 21 August 2006 Accepted 18 September 2006 